\title{
Material Flow Analysis of Electronic Wastes (e-Wastes) in Lagos, Nigeria
}

\author{
Fatima Badiru Ibrahim ${ }^{1}$, Donatus Begianpuye Adie ${ }^{1}$, Abdul-Raheem Giwa ${ }^{2}$, Sule Argungu Abdullahi ${ }^{1}$, \\ Charles Amen Okuofu ${ }^{1}$
}

${ }^{1}$ Department of Water Resources \& Environmental Engineering, Ahmadu Bello University, Zaria, Nigeria; ${ }^{2}$ Department of Textile Science and Technology, Ahmadu Bello University, Zaria, Nigeria.

Email: ummulbilkis@yahoo.co.uk

Received May 23 ${ }^{\text {rd }}, 2013$; revised June $25^{\text {th }}$, 2013; accepted July 22 ${ }^{\text {nd }}, 2013$

Copyright (c) 2013 Fatima Badiru Ibrahim et al. This is an open access article distributed under the Creative Commons Attribution License, which permits unrestricted use, distribution, and reproduction in any medium, provided the original work is properly cited.

\begin{abstract}
The fate of end-of-life electronics (e-wastes) is of increasing concern because of their toxicity and ever increasing volumes. Addressing these concerns requires proper management plans and strategy which in turn requires reliable estimates of e-waste generation in the present as well as future times. In this study, a material flow model for the analysis of e-waste generation from computer equipments in Nigeria has been developed. Data used to develop the model are the sales data from major distributors of electronics, usage time of computer equipments and transfer coefficients of the electronics from one stage to another. The analysis of individual flows of computer from the material flow model showed that the fate of obsolete computer equipments were storage (41\%), reuse (35\%) and direct disposal (24\%). The projections of the flows for a period of 15 years also indicated that storage and reuse of computer equipments would be preferred over direct disposal; and computer equipments would continue to remain in either storage, re-use or gradually disposed off for about 11 years after its inflow. This delay or staggering disposal is of advantage as it would reduce the amount of e-waste disposed yearly and also afford the country some time to make plans to accommodate and manage the e-wastes generated more efficiently.
\end{abstract}

Keywords: e-Waste; Material Flow Model; Computer Equipment; Nigeria

\section{Introduction}

The fast growing use of Information and Communication Technology (ICT) and rapid turnover in technology is creating a growing electronic waste (e-waste) stream not only in industrialized but also in developing countries like Nigeria. The challenge is even of greater concern in Nigeria because Nigeria lacks the capacity for handling and recycling the hazardous materials contained in e-waste.

The continuous dependence on electronic equipments in homes and at workplaces as well as rapid changes in technology, changes in media (tapes, software, etc), falling prices, and planned obsolescence has resulted in a fast-growing surplus of electronic waste around the globe [1]. According to [2], the average lifespan of a new model computer has decreased from 4.5 years in 1992 to an estimated 2 years in 2005 and is further decreasing. The United Nations estimates that, collectively, the world generates 20 - 50 million tonnes of e-waste every year [3]. The minimization or elimination of these e-wastes is now of greater concern to the world at large.
The lack of capacity for handling and recycling the hazardous materials contained in e-waste usually leads to the disposal of both e-waste and municipal wastes in the same dumpsites; thereby polluting the environment with heavy metals such as $\mathrm{Cd}, \mathrm{Pb}, \mathrm{Hg}$, and chemicals like polychlorinated dibenzo-p-dioxins (PCDDs) and furans (PCDFs), polybrominated diphenyl ethers (PBDEs) and polycyclic aromatic hydrocarbons (PAHs) thereby creating health risks to the nearby community and the population at large [4]. Thus improper management of e-wastes at the end of its useful life poses serious challenges to the existing solid waste management structures resulting in widespread contamination of the environment. Also, the e-wastes from developed countries which are exported into developing countries in the name of free trade [5] are further complicating the problems associated with ewaste management.

Nigeria is currently undergoing a rapid advancement in information and communication technology (ICT). A very significant proportion of ICT users in Nigeria rely 
on secondhand equipment from developed countries, primarily from Europe and North America. The material flow of secondhand and scrap EEE into Nigeria, the current management practices for such wastes in the country and the environmental and health implications of such low-end management practices have been reviewed by [6, 7]. According to their report, the crude recycling and material recovery processes that have resulted in environmental pollution in countries like India and China which expose millions of people to toxins are yet to catch up in Nigeria. Also, a recent report by [8] on e-waste management in developing countries focusing on Africa categorized Nigeria as one of the promising countries for the introduction of pre-processing technologies if the informal sector is given strong support in capacity building through technology and knowledge exchange.

An estimated 400,000 units of second hand desktop computers (PCs or CRTs) are imported into Nigeria every month [6,7]. Meanwhile, the trading of secondhand electronics is currently booming at the famous "computer village” in Lagos, Nigeria owing to this large-scale importation of secondhand electronics. Brokers and traders from countries in the West African sub-region come to Lagos to buy secondhand computers and their accessories as well as other electronic devices. As a result, a substantial quantity of these imports may be diverted to other African countries, especially countries in the ECOWAS sub-region.

Various authors have asserted that lack of reliable data is a major challenge to e-waste estimation and management $[2,9,10]$. This situation is not different in Nigeria because the magnitude and flow of e-waste is not well known and the data on the local generation of e-waste and on the inflow of new electronics are scarce [6]. Hence, it is an opportune time for Nigeria to start addressing the problem of increasing e-waste volumes because neglecting the fact of growing e-waste volumes bears the risk of a developing informal sector, with all its social and environmental drawbacks.

This study is carried out in Lagos, the former capital of Nigeria due to the large inflow of electronics into the country through the state; and also because it is a trade center for computers for other West African countries. This study intends to fill the gap of the flow of e-wastes as well as determination of the fate of obsolete electronics equipments in the study area with a view to providing the information obtained to policy makers and researchers for use in drawing up management plans for e-wastes in the country.

\section{Materials and Methods}

\subsection{Geographical Scope of Nigeria}

Nigeria is situated in West Africa; Nigeria has an area of
$923,768.00 \mathrm{sq}$ kilometers and lies between latitude $40^{\circ}$ and $140^{\circ}$ North of the equator and longitudes $30^{\circ}$ and $140^{\circ}$ East of the Greenwich meridian. The use of ICT is more concentrated in the urban centers of the country than in the semi-urban and rural areas. In this regard, this study focuses the e-waste generation and management in one of the major urban centres in Nigeria; Lagos metropolis.

\subsection{Material Flow Analysis of Obsolete Computer Equipments}

The method developed at Carnegie Mellon University [11] was used for the material flow analysis in this study. Also the study of $[12,13]$ had some influence on the choice of processes that were included in the model. These processes are the re-use and storage parameters of obsolete computer equipments which delay their entry into the waste stream.

\subsection{Modeling Software}

Microsoft Excel has been chosen as the modeling software mainly for the reason that it is relatively simple to use and commonly available.

\subsection{The Model Input}

The inputs for the model are; sales data, usage times of computer equipments and the transfer coefficients as illustrated in Figure 1.

- Importation and sales data for the goods considered in the model (desktops and laptops) constitute the inflow of the model.

- Usage times per process determine the time a good remains in one process.

- Transfer coefficients determine how a good is partitioned when more than one flow exists after a process.

\subsection{Estimation Equations for the Material Flow Model}

Amount in storage: the amount of computer equipments

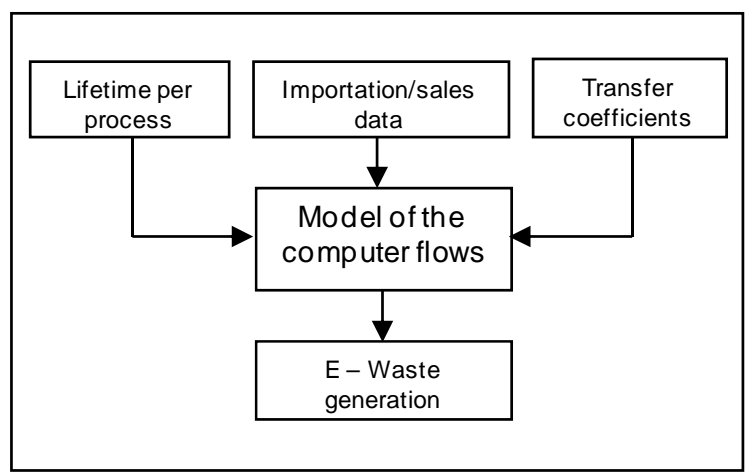

Figure 1. Principal data flow through the model. 
in storage at a time (t) in terms of inflow of computer items is the sum of the amount stored from obsolete computers that were bought 4 years ago, the amount stored from obsolete items bought 5 years ago which are now in their second year in storage and the amount in second storage.

The amount in second storage is calculated as half of the obsolete items from re-use which is obtained as the sum half of items that was reused from the items bought 7 years ago (without $1^{\text {st }}$ storage), 8 years ago (without $1^{\text {st }}$ storage but in their $2^{\text {nd }}$ year in $2^{\text {nd }}$ storage), those bought 9 years ago (with $1^{\text {st }}$ storage and in their $1^{\text {st }}$ year in second storage) and 10 years ago (with $1^{\text {st }}$ storage but in their second year in $2^{\text {nd }}$ storage).

This is represented in Equation (1) below:

$$
\begin{aligned}
S T(t)= & \left(k_{s 1} * A_{t-4}\right)+\left(K_{s 1} * A_{t-5}\right)+\alpha_{1}\left(k_{r} * A_{t-7}\right) \\
& +\alpha_{2}\left(k_{r} * A_{t-8}\right)+\alpha_{3}\left(k_{r} * A_{t-9}\right)+\alpha_{4}\left(k_{r} * A_{t-10}\right)
\end{aligned}
$$

where $S T(t)$ = total amount of obsolete computer equipments in storage in the year $t$.

$A_{(t)}=$ the quantity of computer equipments imported/ sold for the year $(t)$.

$k_{s 1}=$ transfer coefficient of computer flows from corporate organizations, small business and households into $1^{\text {st }}$ storage.

$k_{r}=$ transfer coefficient of computer flows from corporate organizations, small business and households into $1^{\text {st }}$ re-use.

$t=$ the current year.

$\alpha_{1}, \alpha_{2}, \alpha_{3}, \alpha_{4}=$ fractions or percentage that goes into re-use after first storage from computer equipments bought 7, 8, 9, and 10 years ago respectively.

Amount in Re-use: the amount of computers in re-use at a time $t$ is obtained as the sum of the fraction of items re-used from the items bought 4 years ago (without $1^{\text {st }}$ storage), 5 years ago (without $1^{\text {st }}$ storage but in their second year in re-use), 6years ago (without $1^{\text {st }}$ storage but in their $3^{\text {rd }}$ year in re-use) and that of fractions of items that are in re-use from $1^{\text {st }}$ storage.

The amount of items that go into re-use from $1^{\text {st }}$ storage is obtained as the sum of half of items re-used from items bought 6 years ago that have been stored (storage 1) for 2 years, half of obsolete items bought 7 years ago from storage 1 (which are now in their $2^{\text {nd }}$ year in re-use) and half of obsolete items bought 8 years ago from storage 1 (which are now in their $3^{\text {rd }}$ year in re-use).

$$
\begin{aligned}
R u_{(t)}= & \left(k_{r} * A_{t-4}\right)+\left(K_{r} * A_{t-5}\right)+\left(k_{r} * A_{t-6}\right) \\
& +\beta_{1}\left(k_{s 1} * A_{t-6}\right)+\beta_{2}\left(k_{s 1} * A_{t-7}\right)+\beta_{3}\left(k_{s 1} * A_{t-8}\right)
\end{aligned}
$$

where $R u_{(t)}=$ the total amount of computer equipments in re-use in the year $t$

$\boldsymbol{\beta}_{1}, \boldsymbol{\beta}_{2}, \boldsymbol{\beta}_{3}=$ fractions or percentage that goes into first storage after first use from computer equipments bought
6, 7, and 8 years ago respectively.

Amount disposed: the amount of obsolete computer equipments to be disposed at a time $t$ is obtained as the sum of obsolete items disposed after $1^{\text {st }}$ use from corporate organizations, small businesses and households as well as those from $1^{\text {st }}$ storage, $2^{\text {nd }}$ storage and reuse. This is shown in equation 3 below.

$$
\begin{aligned}
D p_{(t)}= & \left(k_{d} * A_{t-4}\right)+\left(K_{s 1 d} * A_{t-6}\right)+\left(k_{r d} * A_{t-7}\right) \\
& +\left(k_{r d} * A_{t-9}\right)+\left(k_{r s 2} * A_{t-11}\right)
\end{aligned}
$$

where $D p_{(t)}=$ amount of obsolete computer equipments disposed in the current year $(t)$.

$k_{d}=$ transfer coefficient of computer flows from corporate organizations, small business and households into disposal after 1st use.

$k_{s 1 d}=$ transfer coefficient of computers from $1^{\text {st }}$ storage to disposal.

$k_{r d}=$ transfer coefficient of computers from reuse to disposal.

$k_{r s 2}=$ transfer coefficient of computers from re-use to second storage.

\subsection{Model Scenarios}

Three scenarios were developed for the prediction of e-waste to be generated from computer equipments in the study area for the year 2011-2025. The first scenario is based on the data obtained from the present study while the second and third scenarios present the best and worst cases respectively. The best and worst case scenarios are designed to determine what could be the maximum and minimum e-waste generation from computer equipments in the study areas in the next fifteen years. The three scenarios are described as follows and summarized in Table 1:

Scenario 1: from collected data

This scenario is based on the data sources presented in Tables 1 to 3 . The model inflow was based on the sales data of major distributors in the study area while the us-

Table 1. Summary of the model scenarios for computer equipments used in the model.

\begin{tabular}{cll}
\hline \multicolumn{1}{c}{ Scenario } & \multicolumn{1}{c}{ Features } \\
\hline 1: from collected data & - & \multicolumn{1}{c}{$\begin{array}{l}\text { Data from questionnaires } \\
\text { Polynomial growth of computer sales }\end{array}$} \\
2: best case & - & $\begin{array}{l}\text { Longer lifespan } \\
\text { Re-use and storage preferred over } \\
\text { direct disposal }\end{array}$ \\
& - & $\begin{array}{l}\text { Growth rate is } 10 \% \text { less than scenario } 1 \\
\text { 3: worst case }\end{array}$ \\
& - & $\begin{array}{l}\text { Shorter lifespan } \\
\text { Direct disposal preferred over re-use } \\
\text { and storage } \\
\text { Growth rate is } 20 \% \text { above that } \\
\text { of scenario } 1 .\end{array}$ \\
\hline
\end{tabular}


Table 2. Sales Data from 2007 to 2011 and their Projection until 2025.

\begin{tabular}{cccccc}
\hline Year & Desktop & Laptop & Year & Desktop & Laptop \\
\hline $\mathbf{2 0 0 7}$ & 43500 & 50500 & $\mathbf{2 0 1 7}$ & 258421 & 342369 \\
$\mathbf{2 0 0 8}$ & 44000 & 55750 & $\mathbf{2 0 1 8}$ & 301181 & 402779 \\
$\mathbf{2 0 0 9}$ & 49750 & 67250 & $\mathbf{2 0 1 9}$ & 348120 & 468653 \\
$\mathbf{2 0 1 0}$ & 58750 & 84500 & $\mathbf{2 0 2 0}$ & 399237 & 539992 \\
$\mathbf{2 0 1 1}$ & 72250 & 106000 & $\mathbf{2 0 2 1}$ & 454533 & 616794 \\
$\mathbf{2 0 1 2}$ & 107299 & 122284 & $\mathbf{2 0 2 2}$ & 514008 & 699061 \\
$\mathbf{2 0 1 3}$ & 129166 & 155372 & $\mathbf{2 0 2 3}$ & 577661 & 786793 \\
$\mathbf{2 0 1 4}$ & 155212 & 193925 & $\mathbf{2 0 2 4}$ & 645492 & 879988 \\
$\mathbf{2 0 1 5}$ & 185437 & 237942 & $\mathbf{2 0 2 5}$ & 717503 & 978648 \\
$\mathbf{2 0 1 6}$ & 219840 & 287424 & & & \\
\hline
\end{tabular}

The italic figures are the projections made assuming a polynomial trend growth.

Table 3. Usage times of computer equipments used in the processes of the model.

\begin{tabular}{ccc}
\hline & \multicolumn{2}{c}{$\begin{array}{c}\text { Lifetime of computer equipment } \\
\text { per process (years) }\end{array}$} \\
\cline { 2 - 3 } & Desktops & Laptops \\
\hline Corporate Organizations & 4 & 4 \\
Small Businesses & 4 & 3 \\
Households & 4 & 3 \\
Re-use & 3 & 3 \\
Storage after $1^{\text {st }}$ use & 2 & 2 \\
Storage after $2^{\text {nd }}$ use & 2 & 2 \\
\hline
\end{tabular}

age times and transfer coefficients were obtained from the questionnaires.

\section{Scenario 2: best case}

The best case assumes a longer lifespan or usage time and flows of computer equipments to storage and re-use are favoured over flows to direct disposal. Also, the growth of computer market for the specified period is assumed to be $10 \%$ less than scenario 1 .

\section{Scenario 3: worst case}

The worst case scenario assumes the opposite of the best case scenario, hence, shorter lifespan for computer equipments and a preference of the flows to direct disposal as well as a growth of the computer market of $20 \%$ above that of scenario 1 were used.

\section{Results and Discussion}

\subsection{Model Inflow Data}

\subsubsection{Sales Data}

The sales data for desktop and laptop computers obtained from questionnaires received from distributors/retailers from the study areas were used as inflow to the model. Five (5) years data was obtained for the year 2007-2011 from 16 distributors/retailers in Lagos metropolis. The quantities of Laptops and desktops sold within these five years by the distributors/retailers were extrapolated to 2025 using the most appropriate trend lines. The polynomial trend lines gave the best fit $\left(\mathrm{R}^{2}=0.999\right)$ for laptop and desktop growth in Lagos as shown in Figure 2 and the actual values given in Table 2.

\subsubsection{Usage Times}

The usage times of computer equipments in the individual processes of the model was obtained from the questionnaires administered to consumers of computer equipments (Table 3). However, sufficient data was not available on the storage times of computer equipments after re-use, therefore it was estimated that storage after reuse is 2 years.

\subsubsection{Transfer Coefficients}

The transfer coefficients (Table 4) were also obtained from the information compiled from the questionnaires. The transfer coefficients of computer equipments from sales to the consumers (i.e. corporate organizations, small businesses and households) were obtained from the information gathered from the distributors on percentage of their sales to each of the three consumer groups while the transfer coefficients from each of the consumers to $1^{\text {st }}$ storage, re-use and disposals were deduced from the questionnaires issued to the consumers. There is however insufficient information on the fate of equipments after re-use and second storage. It was therefore estimated that half $(50 \%)$ of computer equipments are disposed after reuse while the other half is stored further ( $2^{\text {nd }}$ storage). It was also assumed that all (100\%) of computer items are disposed after second storage.

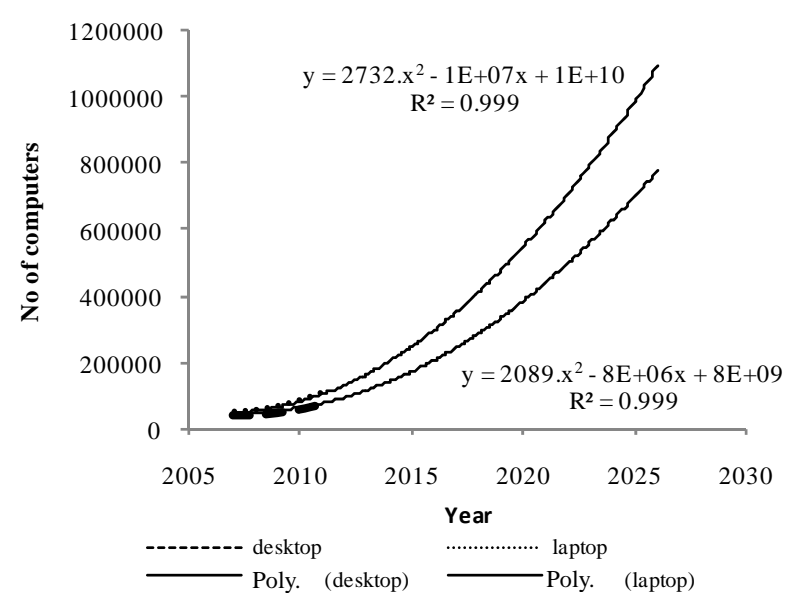

Figure 2. Extrapolation of the sales data obtained from distributors/retailers in the study area using polynomial trend. 
Table 4. Transfer coefficients.

\begin{tabular}{ccccc}
\hline \multicolumn{5}{c}{ Transfer coefficients for computer equipments used } \\
in the model
\end{tabular}

\subsection{Analysis of Individual Flows}

The individual flows for each year was analyzed in order to determine the quantity of flows to storage, re-use and direct disposal after $1^{\text {st }}$ use as illustrated in Figure 3 . The summary of the flows from the consumption phase after $1^{\text {st }}$ use as shown in Table 5 below indicates that the most important flows are to storage (41\%) and reuse (35\%) while the flows to disposal is comparatively lower (24\%). This is consistent with similar works from developing countries [14-16] where storage is the major means of managing e-wastes due to lack of take back systems. In Nigeria, this pattern of flow can be attributed to the reluctance of consumers to dispose off their out of use electronics because of the high cost of electronic equipments and hope that it could be repaired or reused somehow in the future.

The results of the material flow analysis showing the quantities of computer equipments to be stored, reused and disposed in Lagos from 2007-2036 are as given in Table 6.

The results indicate that the quantity of computers that moves into storage, reuse and disposal increased proportionately with the demand (sales) of computer equipments (as illustrated in Table 2). The quantity of computer equipments to be stored and reused in Lagos from 2012-2036 was observed to be almost equal and much higher than those for disposal.

The table also shows that quantities of computers in storage, reuse as well as those to be disposed continue to increase until four years after the last inflow (i.e.
Table 5. Fate of obsolete computer equipments after $1^{\text {st }}$ use from the MFA.

\begin{tabular}{cc}
\hline Fate of computer equipment after $\mathbf{1}^{\text {st }}$ use & Percentage \\
\hline Storage & $41 \%$ \\
Reuse & $35 \%$ \\
Disposal & $24 \%$ \\
\hline
\end{tabular}

2025-2029) after which their values start to drop (due to lack of inflow).The result also indicated that computer equipments continue to remain in either storage, re-use or gradually disposed off for 10, 8 and 11 years respectively after its inflow into the consumption phase. The additional lifespan of computer equipments in storage and reuse delay and reduce the quantity that is eventually disposed off yearly.

\section{Scenario Comparison}

The scenario analysis of e-waste generation from computer equipments (desktops and laptops) sold in Lagos as obtained from questionnaires and forecasted from 2012-2025 is presented in Figure 4. The result shows that the present scenario(scenario 1 ) is quite similar to the best case scenario (scenario 2) which suggests that the current e-waste management situation in Lagos is such that allows a relatively minimal amount of e-wastes to be disposed directly into dumpsites or landfills. This could be attributed to the fact that trade in secondhand computers and computer parts are well established in Lagos, hence most of the parts are reused in cloning new ones or sold to recyclers. However this is most likely to be peculiar to Lagos alone, other parts of the country where the trade is not well established may face the risk of having a scenario whereby a higher rate of disposal may be experienced.

Also the graph shows that the implication of computers having shorter life spans (as in scenario 3) is increase in the rate and quantity of e-waste generation.

For a country like Nigeria where recycling facilities for e-wastes are not yet available, storage and reuse of obsolete electronic equipments should be encouraged because e-waste disposal would be delayed and disposed off gradually. This will afford the country the time to make plans to accommodate and manage the e-wastes to be disposed off more efficiently rather than having scenario whereby a large quantity of e-waste is disposed in a relatively shorter time.

\section{Conclusion}

This study has shown that the demand for electronics equipments and ultimately, the quantity of e-wastes generated will continue to increase in Nigeria as it is shown by the growth trend in the sales of computer equipments. 


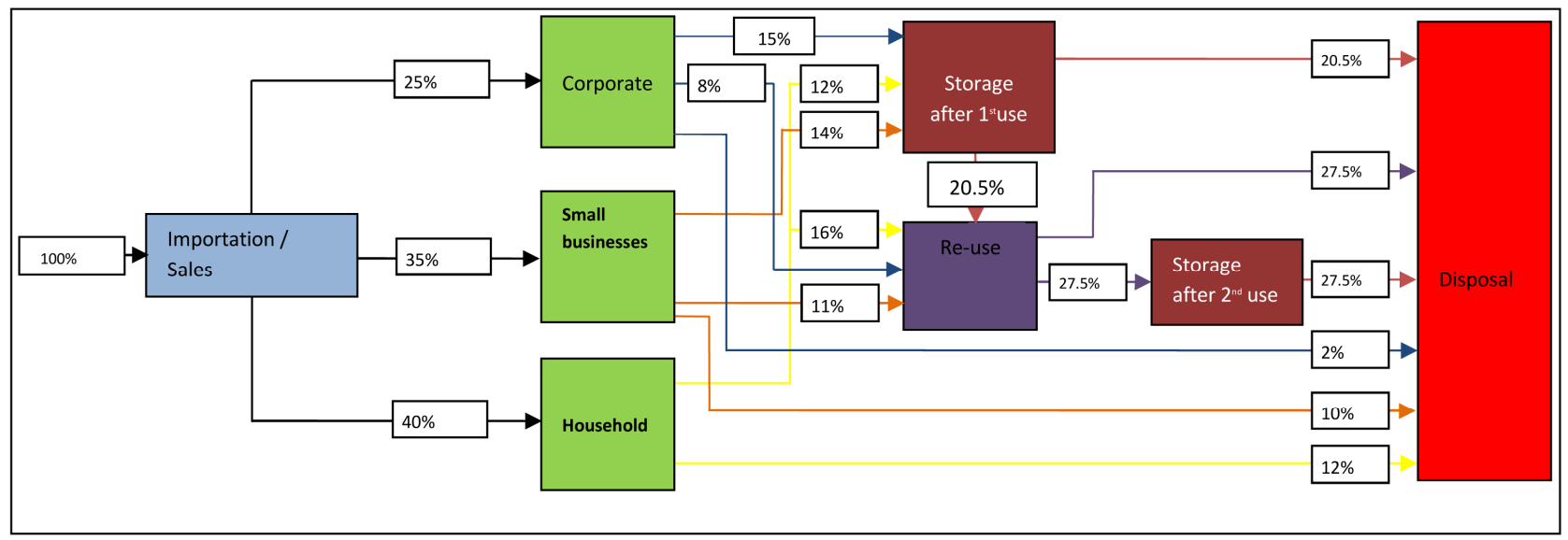

Figure 3. Analysis of individual flows of computers in Lagos.

Table 6. Quantity of computer equipments to be stored, reused and disposed from 2011-2036.

\begin{tabular}{|c|c|c|c|c|c|c|c|c|}
\hline \multirow{2}{*}{ Year } & & & \multicolumn{2}{|c|}{ Quantity disposed } & \multicolumn{2}{|c|}{ Quantity in reuse } & \multicolumn{2}{|c|}{ Quantity in storage } \\
\hline & & & Desktop & Laptop & Desktop & Laptop & Desktop & Laptop \\
\hline 2007 & 43500 & 50500 & 0 & 0 & 0 & 0 & 0 & 0 \\
\hline 2008 & 44000 & 55750 & 0 & 0 & 0 & 0 & 0 & 0 \\
\hline 2009 & 49750 & 67250 & 0 & 0 & 0 & 0 & 0 & 0 \\
\hline 2010 & 58750 & 84500 & 0 & 0 & 0 & 0 & 0 & 0 \\
\hline 2011 & 72250 & 106000 & 9896 & 11489 & 11854 & 13761 & 17835 & 20705 \\
\hline 2012 & 107299 & 122284 & 10010 & 12683 & 23844 & 28953 & 35875 & 43563 \\
\hline 2013 & 129166 & 155372 & 11318 & 15299 & 46318 & 57631 & 38438 & 50430 \\
\hline 2014 & 155212 & 193925 & 19293 & 26104 & 59494 & 78325 & 50412 & 69098 \\
\hline 2015 & 185437 & 237942 & 20947 & 29829 & 77391 & 105804 & 65632 & 92582 \\
\hline 2016 & 219840 & 287424 & 35437 & 41593 & 96199 & 127771 & 92315 & 117236 \\
\hline 2017 & 258421 & 342369 & 41402 & 51604 & 121179 & 157385 & 123656 & 148992 \\
\hline 2018 & 301181 & 402779 & 55422 & 71026 & 155584 & 192627 & 147217 & 185926 \\
\hline 2019 & 348120 & 468653 & 67185 & 85775 & 191311 & 238672 & 178913 & 228845 \\
\hline 2020 & 399237 & 539992 & 79876 & 104920 & 233027 & 292681 & 216230 & 279186 \\
\hline 2021 & 454533 & 616794 & 97324 & 125941 & 277170 & 356842 & 259297 & 336910 \\
\hline 2022 & 514008 & 699061 & 114969 & 151633 & 327298 & 428830 & 308069 & 402183 \\
\hline 2023 & 577661 & 786793 & 137498 & 179163 & 383412 & 508647 & 360179 & 476460 \\
\hline 2024 & 645492 & 879988 & 160179 & 211530 & 445513 & 596290 & 417993 & 558196 \\
\hline 2025 & 717503 & 978648 & 185378 & 247189 & 513598 & 691762 & 481511 & 647390 \\
\hline 2026 & 0 & 0 & 213095 & 286141 & 587670 & 795060 & 550732 & 744043 \\
\hline 2027 & 0 & 0 & 243329 & 328385 & 667728 & 906187 & 625657 & 848155 \\
\hline 2028 & 0 & 0 & 276080 & 373921 & 753771 & 1025141 & 706286 & 959725 \\
\hline 2029 & 0 & 0 & 311350 & 422749 & 845800 & 1151922 & 792619 & 1078754 \\
\hline 2030 & 0 & 0 & 168572 & 228539 & 727534 & 991476 & 559242 & 761306 \\
\hline 2031 & 0 & 0 & 190593 & 259020 & 593354 & 808995 & 298618 & 406384 \\
\hline 2032 & 0 & 0 & 214180 & 291550 & 279414 & 381020 & 334448 & 455687 \\
\hline 2033 & 0 & 0 & 157982 & 215146 & 147088 & 200623 & 264414 & 360440 \\
\hline 2034 & 0 & 0 & 176466 & 240541 & 0 & 0 & 185708 & 253239 \\
\hline 2035 & 0 & 0 & 87948 & 119898 & 0 & 0 & 97760 & 133341 \\
\hline 2036 & 0 & 0 & 97760 & 133341 & 0 & 0 & 0 & 0 \\
\hline
\end{tabular}




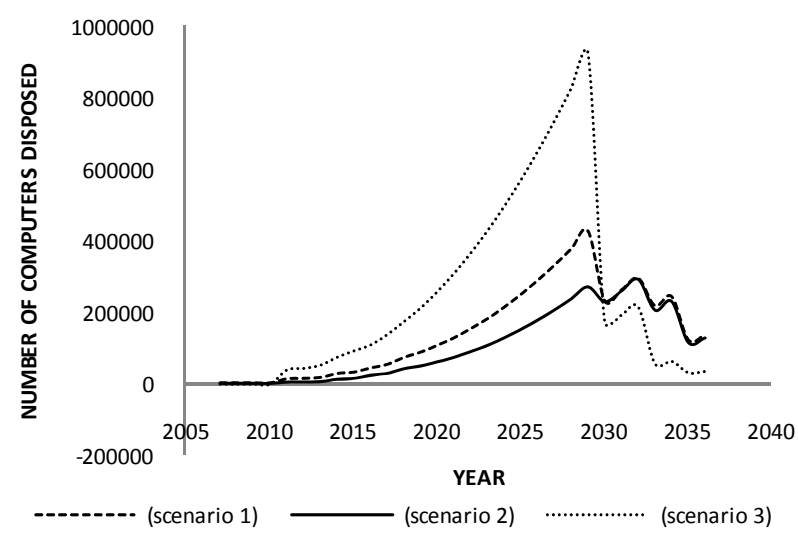

Figure 4. Estimates of E-waste generation from computers in Lagos for scenarios 1-3.

The material flow analysis of computer equipment in Lagos has storage, re-use and direct disposal as end of life options for obsolete equipments, however, the choice for storage and re-use outweigh direct disposal for economic reasons. This current practice of storage and reuse of obsolete electronic equipments give the country the opportunity to plan ahead for the establishment of proper take back programmes, recycling centers as well as other necessary schemes to tackle the problem of e-wastes in Nigeria.

\section{REFERENCES}

[1] N. Prashant, "Cash for Laptops Offers 'Green' Solution for Broken or Outdated Computers,” Green Technology Technology Marketing Corporation, Norwalk, 2008. http://green.tmcnet.com/topics/green/articles/37567-cashlaptops-offers-green-solution-broken-outdated-computers. htm

[2] R. Widmer, H. Oswald-Krapf, A. Sinha-Khetriwal, M. Scnellmann and H. Boni, "Global Perspectives on the e-Waste," Environmental Impact Assessment Review, Vol. 25, No. 5, 2005, pp. 436-458. http://dx.doi.org/10.1016/j.eiar.2005.04.001

[3] S. Schwarzer, et al., "E-waste, the Hidden Side of IT Equipment's Manufacturing and Use,” 2005. http://www.grid.unep.ch/product/publication/download/e w_ewaste.pdf

[4] C. S. C. Wong, S. C. Wu, N. S. Duzgoren-Aydin, A. Aydin and M. H. Wong, "Trace Metal Contamination of Sediments in an e-Waste Processing Village in China,” Environmental Pollution, Vol. 145, No. 2, 2007, pp. 434442. http://dx.doi.org/10.1016/j.envpol.2006.05.017

[5] Toxics Link, "E-Waste in Chennai Time Is Running Out,"
2004. http://www.toxicslink.org

[6] I. C. Nnorom and O. Osibanjo, "Electronic Waste (eWaste): Material Flows and Management Practices in Nigeria,” Waste Management, Vol. 28, 2008, pp. 1472-1479 http://dx.doi.org/10.1016/j.wasman.2007.06.012

[7] BAN, “The Digital Dump: Exporting Re-Use and Abuse to Africa,” In: P. Jim, Ed., Basel Action Network, 2005. http://www.ban.org

[8] M. Schluep, "E-waste Management in Developing Countries-with focus on Africa," ITU Symposium on ICTs and the Environment \& Climate Change, Cairo, 2-3 November 2010.

[9] N. C. Leigh, M. J. Realff, A. Ning, S. P. French, C. L. Ross and B. Brass, "Modeling Obsolete Computer Stock under Regional Data Constraints: An Atlanta Case Study," Resources, Conservation and Recycling, Vol. 51, No. 4, 2007, pp. 847-869.

http://dx.doi.org/10.1016/j.resconrec.2007.01.007

[10] Muller, E., Schluep, M., Widmer, R., Gottschalk, F. and Boni, H. “Assessment of e-Waste Flows: A Probabilistic Approach to Quantify E-Waste Based on World ICT and Development Indicators,” R09 World Recycling Congress, Davos, 2009.

[11] H. Matthews, F. McMichael, C. Hendrickson and D. Hart, "Disposition and End-of-Life Options for Personal Computers,” Design Initiative Technical Report \#97-10, Carnegie Mellon University, Pittsburgh, 1997.

[12] H. Y. Kang and J. M. Schoenung, "Estimation of Future Outflows and Infrastructure Needed to Recycle Personal Computer Systems in California,” Journal of Hazardous Materials, Vol. 137, No. 2, 2006, pp. 1165-1174. http://dx.doi.org/10.1016/j.jhazmat.2006.03.062

[13] B. Steubing, "E-Waste Generation in Chile: Situational Analysis and Estimation of Actual and Future Computer Waste Quantities Using Material Flow Analysis,” Master's Thesis, Swiss Federal Institute of Technology Lausanne, 2007.

[14] A. Bondolfi, “The Green e-Waste Channel: Model for a Reuse and Recycling System of Electronic Waste in South Africa,” Master Thesis, UNI Lausanne/EMPA, 2007.

[15] F. B. Ibrahim, D. B. Adie, A. Giwa and C. A. Okuofu, "E-Waste Generation and Management in Nigeria," Proceedings of The Twenty-Eighth International Conference on Solid Waste Technology and Management CD-ROM, Philadelphia, 10-13 March 2013, pp. 133-142.

[16] S. Ojeda-Benitez, S. E. Cruz-Sotelo, L. Velazquez, N. Santillan-Soto, M. Q. Nunez, O. R. G. Cueto and W. Markus, "Electrical and Electronic Waste in Northwest Mexico,” Journal of Environmental Protection, Vol. 4, 2013, pp. 405-410. http://dx.doi.org/10.4236/jep.2013.45048 